\title{
Effects of type of packaging materials on physicochemical, microbiological and sensory characteristics of durian fruit leather during storage
}

\begin{abstract}
A study on storage stability of durian leather was carried out at room temperature using four types of packaging materials - laminated aluminium foil (LAF), high-density polyethylene (HDPE), low-density polyethylene (LDPE) and polypropylene (PP) films - for 12 weeks. Analyses on physicochemical, microbiological and sensory characteristics were conducted at weeks $0,2,4,8$ and 12. Analyses for sugar, fat and caloric contents were conducted at the beginning and the end of storage period. Moisture contents and water activity $(\mathrm{A}(\mathrm{w}))$ fluctuated during storage but tended to decrease after week 8. Non-enzymatic browning increased significantly $(\mathrm{P}<0.05)$ for all samples in packaging materials used; the highest increases were observed in LDPE-packed leather. The increases were related to the changes in colour of samples during storage. The longer storage time, the higher $L$ and $b$ values and the lower a value. The $\mathrm{pH}$, although it fluctuated in the first weeks, slightly increased at the end of the storage period, while the hardness for each sample gradually increased during the storage. Microbial analyses showed that total mesophilic bacteria (TMB) and total moulds and yeast (TMY) counts were low, where after 12-week storage TMB and TMY were less than 60 and $140 \mathrm{cfu}$ g-1, respectively. Organoleptically, for all attributes evaluated, all samples were acceptable by panelists during the 12-week storage period.
\end{abstract}

Keyword: Clone D24; Durio zibethinus Murr; Organoleptic evaluation; Packaging materials 